\title{
¿SE ABRIRÁN DE NUEVO LAS GRANDES ALAMEDAS?
}

Luis Fernando Medina, El fénix rojo. Las oportunidades del socialismo, Madrid, Los Libros de la Catarata, 2014, 144 páginas

Alberto Castrillón*

De su cuerpo yerto emana calor. Lactancio

$\mathrm{E}$ n su discurso de la mañana del 11 de septiembre de 1973, en el Palacio de la Moneda asediado por los militares golpistas, el presidente Salvador Allende vaticinó: “Se abrirán de nuevo las grandes alamedas por donde pase el hombre libre", palabras hoy labradas en piedra en la estatua situada frente al palacio presidencial.

En este escrito se comenta un libro interesante y polémico. Un libro que también augura el resurgimiento del socialismo y que se refiere a sus posibilidades actuales. Un libro que va a contracorriente de la economía y el pensamiento predominantes en el mundo académico y en los centros de poder. Un libro que además está escrito en lenguaje llano, para el lector corriente, sin sacrificar profundidad, cuya lectura invita a reflexionar, a conversar y a discutir.

Luis Fernando Medina usa la metáfora del fénix para referirse al socialismo, que, igual que esta ave mítica, puede llegar a renacer, y convertirse de nuevo en opción alternativa de la sociedad futura. Aunque el socialismo, a secas, no goza de cabal salud, es prematuro rezar sus responsos. El autor argumenta que el regreso del ideario socialista -así sea con otro nombre- no será resultado del fracaso del capitalismo ni de eventos como la crisis actual, que algunos llaman Gran Recesión. Por el contrario, para él “serán los éxitos del capitalismo, tanto o más

\footnotetext{
* Maestría en Desarrollo Económico, profesor de la Universidad Externado de Colombia, Bogotá, Colombia, [jracastrillon@yahoo.com]. Fecha de recepción: 21 de marzo de 2016, fecha de modificación: 16 de abril de 2016, fecha de aceptación: 12 de mayo de 2016. Sugerencia de citación: Castrillón, A. "¿Se abrirán de nuevo las grandes alamedas?”, Revista de Economía Institucional 18, 34, 2016, pp. 341-351. DOI: http://dx.doi.org/10.18601/01245996.v18n34.20
} 
que sus fracasos, los que le den fuerza al socialismo". La tesis que defiende en este libro es que "las actuales tendencias del capitalismo generan un entorno propicio para que resurja el socialismo como fuerza ideológica” (p. 18). Así el capitalismo goce de buena salud.

\section{EL AVE FÉNIX}

Claudio Claudiano, uno de los últimos poetas latinos -murió en el año 405- dice que el fénix "es un ave igual a los dioses celestes, compite con las estrellas en su forma de vida y en la duración de su existencia, vence el curso del tiempo con el renacer de sus miembros. No sacia su hambre comiendo ni apaga su sed con fuente alguna". Pocos símbolos más adecuados que el ave fénix para referirse a hechos que, como un ideal que se niega a desaparecer, siempre acompañarán a la humanidad. La aspiración a la justicia y a la libertad es imperecedera. Incluso en tiempos de barbarie y desolación, de eclipse de los más preciados valores humanistas. Como recuerda Johan Huizinga: “Toda época suspira por un mundo mejor. Cuanto más profunda es la desesperación causada por el caótico presente, tanto más íntimo es este suspirar".

El pavor que hoy causa la palabra "socialismo" es alucinante. En Estados Unidos un político de centro como el presidente Obama debe aclarar a la derecha republicana y al Tea Party que no es socialista, y un representante de la oligarquía colombiana, como el presidente Santos, debe jurar y dar fe a la derecha colombiana -horra de honestidad y cargada de impudicia- que no conspira para entregar el país a la guerrilla, como parte de un plan continental urdido en el extranjero. A 25 años de la caída del Muro de Berlín y a más de 40 del inicio del desmantelamiento del Estado de Bienestar, ese espectáculo-que en otra época sería ridículo- trae a la memoria las palabras de Jules Michelet al recordar la Revolución Francesa: "Llama, cómo debiste ser cuando tus cenizas queman todavía”.

\section{EL CALOR DEL CUERPO YERTO}

E1 epígrafe de este escrito se atribuye a Lactancio, poeta y apologista cristiano, animado por la esperanza de un renacer. Como parece estarlo el autor de este libro, aunque el socialismo parezca estar en su nadir histórico, tanto en su versión leninista como en cualquier otra. Declararse "socialista" - dice- es hoy similar a declararse "rosacrucista”: anacrónico e incomprensible. Quizá el movimiento socialista no recobre la fuerza de antaño, pero aún puede erigirse en una visión 
alternativa de la sociedad del futuro, aunque no se la promueva con el nombre de socialismo.

Entre sus cenizas aún quedan rescoldos. Entre las figuras protagónicas de la Primera Guerra Mundial, cuyo centenario acabamos de conmemorar-Francisco José de Austria, Woodrow Wilson, Georges Clemenceau, el Kaiser Guillermo, David Lloyd George- solo una de ellas no ha desaparecido de los anaqueles de las bibliotecas, y su imagen aún aparece en pancartas y manifestaciones políticas: Vladimir Ilich Lenin, pese a las denuncias de los crímenes, el terror y la represión en la Unión Soviética. Es llamativo que no se hayan hecho esfuerzos similares para denunciar el papel de Winston Churchill en las "hambrunas y atrocidades" cometidas en India ni el papel de Mandela al frente de un movimiento insurgente ni la ingenuidad de Gandhi ante los nazis. Todo ello ha sido convenientemente olvidado en las historias de Inglaterra, Sudáfrica e India.

La persistencia del recuerdo de Lenin hay que atribuirla -dice Medina-, no a sus atributos personales, tampoco a sus ejecutorias, tan reprensibles y criticables, sino a las particularidades del movimiento político al que perteneció: “¿Podría ser, acaso, que el socialismo no ha desaparecido del todo y que los tenues aleteos que sigue dando en distintos sitios del planeta no son solo el fin de un ciclo, sino el comienzo de otro?" (p. 13). La verdad es que, así las pocas estatuas que aún existen de Lenin sean demolidas, el aliento del proyecto socialista seguirá animando y dando color a las opciones de futuro.

Sus cenizas aún arden, así parezcan frías o aun yertas. E1 difunto Paul Samuelson rechazó "el legado envenenado" de Friedman y Hayek; Warren Buffet habla de "lucha de clases" en Estados Unidos; Paul Krugman va a las manifestaciones de Occupy Wall Street; Joseph Stiglitz simpatiza con el movimiento de los Indignados; Thomas Piketty se vuelve célebre después de reeditar a Marx en 2008; Bernie Sanders, senador de Vermont, no se avergüenza de proclamarse "socialista" y disputa a Hillary Clinton la nominación por el partido demócrata a la presidencia de Estados Unidos; Jeremy Corbyn lidera el Partido Laborista en Inglaterra -para pasmo de Tony Blair, quien solo pudo decir "no estoy seguro de entender del todo la política" ante este renacer de la tradición laborista-.

Entre la muerte de Marx (1883) y la instauración de la Unión Soviética (1917) apenas trascurrieron 34 años. Otros tantos después, en 1951, el comunismo se extendía desde Berlín hasta Pekín. Una tercera parte de la humanidad vivía bajo los principios del marxismoleninismo, bien fuese por una revolución interna o por la imposición 
del Ejército Rojo, una expansión más rápida que la del cristianismo y la del Islam. En el resto del mundo, el socialismo -en alguna de sus variantes- despertaba esperanzas y ponía coto a las desmesuras del capitalismo.

Igualmente rápida, pero menos espectacular, fue su caída. En los años setenta Enrico Berlinguer, dirigente del Partido Comunista Italiano, advirtió que la "fuerza propulsora" de la Revolución de Octubre estaba agotada. Dos décadas después, el comunismo se había desplomado en Moscú, en Berlín y en los demás países de Europa Oriental donde fue impuesto después de la Segunda Guerra Mundial.

No obstante esa breve y trágica historia, Medina argumenta que "las actuales tendencias del capitalismo generan un entorno propicio para que resurja el socialismo como fuerza ideológica", es decir, como visión que puede impulsar la búsqueda de una sociedad alternativa. Los éxitos del capitalismo, más que sus fracasos, devolverán al socialismo el vigor perdido, aunque el movimiento "socialista" siga perdiendo fuerza y sus principios, sus categorías, su lenguaje y sus propuestas se tornen cada vez menos significativos. Es posible incluso -dice Medina- que en el futuro surjan defensores de esta visión alternativa que no se declaren socialistas. Pero se reconocerá en ellos la impronta de una tradición que se remonta a los inicios del mundo moderno.

\section{¿POR QUÉ EL SOCIALISMO?}

Las revoluciones -la Revolución Francesa, el brote revolucionario de 1848, la revolución haitiana o la Revolución de Octubre- siempre causan temor entre las élites establecidas, así se hayan alzado en armas para llegar al poder o las usen para oponerse a sus adversarios. Las élites también pueden atemorizar a la población con el fantasma de una revolución, o de complots a hurtadillas, para impedir cualquier avance social, por pequeño que sea, como sucede en Colombia, donde los señores de la tierra agitan el espantajo "castrochavista" no para evitar una profunda reforma social o económica sino para oponerse a la reparación de miles de víctimas despojadas de su honra, su vida y sus bienes por agrupaciones al margen del Estado alentadas por el mismo establecimiento. Hace 80 años la élite terrateniente y conservadora agitó el fantasma del comunismo para oponerse a las tímidas pero necesarias reformas del presidente Alfonso López Pumarejo, a quien se intentó desacreditar acusándolo de "agente" de Moscú. La oposición a esas reformas agravaría los problemas del campo y después vendrían décadas de violencia. Antes de la Revolución Cubana y del socialismo bolivariano. Nuestras élites retardatarias no son las únicas 
que hacen acusaciones ridículas para oponerse al cambio. En Estados Unidos, los opositores al New Deal y los periódicos conservadores también tacharon de comunista a Franklin Delano Roosevelt.

Desde mediados del siglo XIX, a medida que el capitalismo, avanzado o no, daba forma y color a las relaciones económicas, sociales y políticas en todo el mundo, también creaba miseria y bolsones proletarios que tendían a simpatizar y a defenderse recurriendo a partidos de izquierda o socialistas. Por ello, a finales de la década de 1920 la Internacional Comunista ya tenía afiliados en los cinco continentes. Pero eso es parte de la historia, una historia que no ha terminado. No basta, como decía Nietzsche, que un "estamento bárbaro de esclavos [...] haya aprendido a considerar su existencia como una injusticia y [...] se disponga a tomar venganza no solo para sí, sino para todas las generaciones" $(2004,156)$. La rápida expansión del socialismo -dice Medina- es inseparable de las virtudes poiéticas, polisémicas y taumatúrgicas del socialismo, virtudes que para bien o para mal impulsaron la creación de sociedades regidas por normas distintas a las del capitalismo de la época. Además, el socialismo proporciona una Weltanschauung, una forma racional de ver el mundo y muchas maneras de reconstruirlo: empresas cooperativas, kibbutz de origen socialista, nacionalización de sectores estratégicos en el Reino Unido, lucha anticolonialista en África, lucha contra el apartheid en Sudáfrica, rebelión palestina, defensa de la mujer, movimiento por los derechos civiles, reducción de la jornada laboral, derecho a negociación colectiva y todo el conjunto de instituciones del Estado de Bienestar. El polisémico socialismo fue el horizonte común de esos proyectos, de esas experiencias, de estas luchas.

\section{¿INVENTARIO DE QUIEBRA?}

Medina observa que hoy el movimiento socialista es débil, ¿quizá latente? En todas sus variantes -socialdemócrata, autogestionario, bolchevique- fue barrido, no por una marejada sino por un tsunami: "a finales del siglo XX todas sus vertientes entraron en declive, sin importar con cuánto ahínco se hubieran deslindado las unas de las otras” (p. 30), qué tanto se hubiesen acercado al liberalismo o qué tan cercanas o distantes estuviesen de Moscú. La derecha ha hecho leña del árbol caído. El rechazo de la intervención del Estado en la economía, a la que los ideólogos liberales confunden deliberadamente con el socialismo, y las reformas orientadas al mercado consiguientes, se han impuesto incluso en países que jamás lograron crear un Estado moderno, que carecían de empresas públicas estratégicas, que apenas 
proporcionaban servicios sociales precarios y que, por supuesto, poco se acercaron a los Estados de Bienestar creados en Europa para preservar el capitalismo de las crisis y del avance del socialismo.

Hoy nada queda a la izquierda, y sin el contrapeso del socialismo realmente existente para la derecha nada es suficiente. La agenda de los republicanos estadounidenses incluye la reducción de los fondos para Medicare, la abolición de la elección popular de senadores, el regreso al voto censitario y la reintroducción del trabajo infantil. Lo que hace apenas tres décadas era un programa de la derecha (la reforma sanitaria de Nixon, p. ej.) hoy se califica de extrema izquierda, y a Barack Obama de comunista e islamista. La defensa de posiciones keynesianas moderadas es indicio de bolchevismo. Sugerir que los impuestos a los ingresos más altos deberían retornar a las tasas de los años noventa es un intento de estrangular a la libre empresa.

Aunque en la lucha política se empleen este tipos de argumentos, no deja de ser un despropósito y una burda manipulación de la historia que los crímenes del estalinismo, de los jemeres rojos o de las Farc se esgriman como un argumento contra cualquier reforma que busque mejorar así sea ligeramente la situación de la mayoría de la población o de los grupos más vulnerables. ¿Las hambrunas propiciadas por los ingleses en Irlanda e India, el genocidio cometido por los belgas en el Congo, la esclavización de las comunidades indígenas en las plantaciones de caucho del Amazonas o la dictadura de Pinochet han suprimido acaso la fe en el capitalismo?

\section{¿QUÉ QUEDA?}

Del ahogado, el sombrero. En los países desarrollados de Europa Occidental las ideas socialistas se amalgamaron con el acervo liberal desde el siglo XIX. Ya en ese siglo XIX el partido socialdemócrata alemán era un partido de masas, con representación en el Parlamento. E1 movimiento se extendió a Escandinavia, Inglaterra, Francia y Austria. Los partidos socialdemócratas han gobernado, solos o en coalición, durante varias décadas -en Suecia durante medio siglo-y, a pesar del tsunami de 1989, aún son una de las principales fuerzas políticas en casi todos los países de Europa Occidental.

Todo lo que hay de amable en el mundo del trabajo es producto del compromiso de los partidos obreros con alguna variante del socialismo. Incluso la política social de Bismarck, forma seminal del Estado de Bienestar, fue motivada por el temor de las élites alemanas a una revolución socialista. En Estados Unidos el New Deal de Roosevelt fue producto de la alianza del Partido Demócrata con el movimiento 
sindical. En fin, el Estado de Bienestar está ligado a la historia del movimiento obrero: erradicación del trabajo infantil, reducción de la jornada laboral, negociación colectiva, salario mínimo, pensiones, seguro de desempleo, voto universal, régimen de sanidad, educación pública, etc. No es casual entonces que el retroceso del Estado de Bienestar y el recorte de los programas sociales en todo el mundo coincidan con el declive del movimiento obrero.

El ciudadano, hijo de la Ilustración, está languideciendo; igual que el socialismo. En la lógica del capitalismo actual los ciudadanos son más o menos prescindibles: solo necesita consumidores. El consumidor remplaza al ciudadano. Llevando la lógica del mercado hasta sus últimas consecuencias, se ha llegado a sostener que los consumidores son los llamados a defender temas de justicia social, como la supresión de la explotación infantil y la preservación del medio ambiente. Serían entonces los consumidores quienes deben controlar a las empresas abusivas y contaminantes. No obstante, como muestra repetidamente la experiencia, el mercado no resuelve esos problemas. La supresión del trabajo infantil, la preservación del medio ambiente y la erradicación de la pobreza en el mundo requieren mucho más que precios correctos. Es imposible resolverlos sin la participación política de la ciudadanía y la existencia de normas legales apropiadas que se hagan cumplir efectivamente.

\section{EL RENACIMIENTO DEL FÉNIX}

La razón para que Medina augure el renacimiento del fénix rojo es precisamente el éxito de la sociedad de consumo. Debido a la abundancia material de las economías modernas el consumo aumenta sin cesar. Pero requiere un "insumo crucial": tiempo libre. Al capitalismo no se le da bien la producción de tiempo libre y ocio para las grandes mayorías. Además, el ocio se ha convertido en negocio; en su contrario, según la etimología latina. El ocio hoy produce grandes ganancias que las empresas de redes sociales se apropian. Sería de esperar que, así como sucedió con los ferrocarriles, cuyas ganancias provenían de sus usuarios y que fueron nacionalizados después de que estos exigieran la redistribución de esas ganancias, ocurra algo similar con la riqueza que genera el ocio: la movilización ciudadana para regular esas actividades.

Por otra parte, el consumo ha cambiado de signo: el capitalismo actual no solo ha transformado la producción. Hoy produce nuevos bienes y servicios, no solo ofrece productos finales, sino paquetes de productos: estilos de vida. Los consumidores generan capital, no son 
meros receptores de capital. El mercadeo azuza el consumo, así como en el siglo XIX el capataz azuzaba a los trabajadores para aumentar las rentas de los patrones.

Por último, las "preferencias de los consumidores" - en contra de lo que proclama la ortodoxia económica- no son santuario de la vida privada. Las preferencias de los individuos son resultado de un proceso colectivo en el que intervienen todos los miembros de la sociedad. Como el socialismo y el institucionalismo han puesto de relieve, el mismo mercado es una construcción social y política. No hay mercados sin Estado. Y es aquí donde las cenizas ardientes pueden conformar de nuevo un pájaro de fuego. La tradición socialista tiene el potencial para trascender la visión del consumidor, incapaz de universalidad. E1 socialismo, como la Ilustración, tiene vocación de universalidad. La vida de los seres humanos no se reduce al consumo y tienen numerosas motivaciones y necesidades que no pueden ser satisfechas por el mercado y la lógica mercantil: "es posible que en la medida en que la sociedad de consumo vaya llevando su propia lógica hasta las últimas consecuencias, se abran paso nuevas visiones de sociedad que tendrán mucho que ver con la tradición socialista” (p. 98).

\section{LA RENTA BÁSICA}

Medina, siguiendo una tradición que se remonta a la Grecia clásica y continúa con la Ilustración y la Revolución de 1789, entiende el socialismo como "una visión de sociedad que of rece a los individuos espacios de cooperación donde puedan encontrarse relativamente a salvo de la presión de los mercados y de los Estados" (p. 110). E1 socialismo y los mercados no siempre han estado bien avenidos, por simplicidades conceptuales y malinterpretaciones de algunas corrientes socialistas. Si de lo que se trata es del "florecimiento del ser humano", es necesario reconocer, una vez que la historia ha despellejado las ilusiones, que los mercados también son "fuente de realización para millones de personas y que todo intento de abolirlos se estrellará contra el comprensible rechazo de aquellos grupos" (p. 111).

Pero ya hemos visto las limitaciones de un orden social de mercado $\mathrm{o}$, si se quiere, de una sociedad en la que la lógica mercantil determina las elecciones del consumidor, no las del ciudadano. En la Crítica del programa de Gotha, Marx señaló el problema medular:

el hombre que no dispone de más propiedad que su fuerza de trabajo, tiene que ser, necesariamente, en todo estado social y de civilización, esclavo de otros hombres, de aquellos que se han adueñado de las condiciones materiales del trabajo. Y no podrá trabajar, ni, por consiguiente, vivir, más que con su permiso (Marx, 1966, 10). 
Y a lo que aspira el socialismo, haciendo eco a la milenaria tradición republicana, es que hombres y mujeres no necesiten pedir permiso a otros para poder vivir. En otros términos, si la libertad precisa condiciones materiales para ser real, si la libertad ha de ser libertad real para todos, el capitalismo no es suficiente. Nada de esto es novedoso: antaño, la medalla del Partido Socialdemócrata Alemán en conmemoración del $1 .^{\circ}$ de mayo mostraba a Karl Marx en una cara y a la estatua de la libertad en la otra. El socialismo no es incompatible con la existencia de mercados. Los mercados son anteriores al capitalismo; fue y sigue siendo posible la existencia de mercados no capitalistas. Además, la propiedad privada no ha sido ni es hoy la única forma de propiedad.

En este punto Medina adhiere a la propuesta de una renta básica universal, una de cuyas variantes es la siguiente:

un ingreso pagado por el estado, como derecho de ciudadanía, a cada miembro de pleno derecho de la sociedad o a cada residente, incluso si no quiere trabajar de forma remunerada, sin tomar en consideración si es rico o pobre o, dicho de otra forma, independientemente de cuáles puedan ser las otras posibles fuentes de renta, $y$ sin importar con quien conviva ${ }^{1}$.

La renta básica universal tiene raíces seculares. Thomas Paine, en Agrarian Justice (1796), escribió sobre la necesidad de crear un fondo nacional, gravando la propiedad privada, para dar una pensión vitalicia de 10 libras esterlinas a toda persona mayor de cincuenta años. Es un derecho fundado - como dice Medina- en el principio de la propiedad colectiva de la riqueza, en la herencia común de la humanidad; es un dividendo social.

En tiempos de crisis, como el actual, la renta básica es además una buena idea, un buen remedio: ayudaría a aliviar los efectos de la peor catástrofe económica desde la Gran Depresión. Pero la reducción de la pobreza no sería su único efecto. La renta básica permitiría que muchos vivieran "sin permiso" de unos pocos. Contribuiría a salvaguardar la libertad individual donde está amenazada por los dueños del capital, o por el Estado. Pues como decía Robespierre, se trata de proteger el "derecho a la existencia"(1794). El socialismo fue inspirado por los ideales de la Ilustración: Libertad, Igualdad, Fraternidad. La renta básica podría sentar las condiciones materiales para que esos ideales se conviertan en realidades No es este el lugar para argumentar sobre su factibilidad ni sobre su financiación. Mucho se ha escrito sobre estos temas.

\footnotetext{
${ }^{1} \operatorname{Ver}[$ http://www.redrentabasica.org/rb/que-es-la-rb].
} 


\section{CRITICA CÓMPLICE}

Sobra decir que comparto las preocupaciones de Luis Fernando Medina: por las crueles consecuencias del capitalismo actual, por las amenazas a la libertad provenientes de los poderes establecidos, por la insolencia de la derecha y el despojo de la herencia común de la humanidad perpetrado por las grandes corporaciones, por la viabilidad del socialismo. En el corto espacio de una reseña, debo hacer sin embargo al menos dos observaciones.

Quizá por los requisitos del ensayo y por razones de exposición, Medina simplifica en exceso la tradición socialista. Por ejemplo, en lo que respecta a la socialdemocracia y al comunismo -vertientes del socialismo- sostiene que no se deben exagerar las diferencias, "como si se tratara de tender un cordón sanitario que ayude a ciertos sectores a mantener la pureza" (p. 12). Por otra parte, el compromiso de la socialdemocracia con los principios de la democracia parlamentaria no obedeció a que en Inglaterra o en Alemania no fuese posible la conquista del poder por las armas. Desde el siglo XIX era clara la separación entre socialistas y comunistas. Baste señalar dos ejemplos, Marie-Ésprit-Léon Walras (1834-1910), padre del equilibrio general, declaró: "Je ne suis pas un économiste; je suis un socialiste", y se reconoció heredero del republicanismo revolucionario de 1789 fundado en el derecho natural. Por su parte, John Stuart Mill, que en su Autobiografía se refiere a su desarrollo mental y a su alejamiento del utilitarismo, en compañía de quien luego sería su esposa, Harriet Taylor, cuenta cómo se acercó al socialismo y se alejó del liberalismo, y expresa claramente sus ideales:

Nuestro ideal de progreso definitivo iba mucho más allá de la democracia y nos clasificaba decididamente bajo la denominación general del socialismo. Aunque repudiábamos con la máxima energía esa tiranía que ejerce la sociedad sobre los individuos en la mayor parte de los sistemas socialistas, esperábamos que llegaría un tiempo en que la sociedad ya no estaría dividida entre los desocupados y los industriosos $(1981,221)$.

E1 siglo XX ha mostrado el gran contraste entre las aspiraciones y la realidad. La hambruna ucraniana provocada por el poder soviético, y la vileza de los comunistas en Alemania y en la Guerra Civil Española, para no mencionar otras atrocidades, hacen necesario tender un "cordón sanitario" entre el comunismo realmente existente y el socialismo republicano. El rechazo del capitalismo desenfrenado y el repudio del totalitarismo son el abono necesario para fertilizar los campos donde se esparcen las cenizas vivificadoras y lograr que se abran de nuevo las grandes alamedas para pasear en libertad. 


\section{REFERENCIAS BIBLIOGRÁFICAS}

1. Hobsbawm, E. Historia del siglo XX, Buenos Aires, Grijalbo-Mondadori, 1999.

2. Judt, T. Postguerra. Una historia de Europa desde 1945, Madrid, Taurus, 2010

3. Marx, K. "Crítica del programa de Gotha” [1875], Marx, K. y F. Engels, Obras escogidas, vol. 2, Moscú, Editorial Progreso, 1966.

4. Mill, J. S. Autobiografía, Madrid, Alianza, 1981.

5. Nietzsche, F. El nacimiento de la tragedia, Madrid, Alianza, 2004.

6. Raventós, D. Las condiciones materiales de la libertad, Madrid, E1 Viejo Topo, 2007. 